\title{
Have Volume-based Parameters of Positron Emission Tomography/Computed Tomography Prognostic Relevance for Patients With Potentially Platinum-responsive Recurrent Ovarian Cancer? A Single Center Italian Study
}

\author{
ANGIOLO GADDUCCI ${ }^{1}$, ENRICO SIMONETTI ${ }^{1}$, FEDERICA GUIDOCCIO $^{2}$, \\ GIANPIERO MANCA ${ }^{2}$, ASSUERO GIORGETTI ${ }^{3}$, TOMMASO DEPALO ${ }^{2}$, \\ STEFANIA COSIO ${ }^{1}$, MARIO MICCOLI $^{1}$ and DUCCIO VOLTERRANI ${ }^{2}$ \\ ${ }^{1}$ Department of Clinical and Experimental Medicine, \\ Division of Gynecology and Obstetrics, University of Pisa, Pisa, Italy; \\ ${ }^{2}$ Regional Center of Nuclear Medicine, Department of Translational Research, University of Pisa, Pisa, Italy; \\ ${ }^{3}$ Fondazione CNR/Regione Toscana "Gabriele Monasterio", Pisa, Italy
}

\begin{abstract}
Background/Aim: To assess the prognostic relevance of volume-based parameters [whole body ( $w b$ )metabolic tumor volume (MTV) and wb-total lesion glycolysis (TLG)] of pretreatment PET/CT in patients with potentially platinum-responsive recurrent ovarian cancer. Patients and Methods: This retrospective investigation analyzed 67 patients at first relapse. Results: At univariate analysis, post-relapse survival and overall survival correlated with residual disease after primary surgery $(R D)$ ( $p=0.015$ and 0.049 , respectively), time to recurrence ( $p=0.005$ and $p=0.0003)$, number of recurrence sites ( $p=0.001$ and $p=0.0005)$, treatment at recurrence $(p=0.044$ and 0.043$)$ and $w b-M T V(p=0.023$ and 0.021$)$ but not with $w b-T L G$. RD, time to recurrence and number of recurrence sites, but not wb-MTV, were independent prognostic variables for post-relapse survival, and time to recurrence and number of recurrence sites, but not wb-MTV, were independent prognostic factors for overall survival. Conclusion: Volume-based parameters of PET/CT are not independent predictors of clinical outcome in potentially platinum-responsive recurrent ovarian cancer.
\end{abstract}

This article is freely accessible online.

Correspondence to: Angiolo Gadducci, MD, Department of Clinical and Experimental Medicine, Division of Gynecology and Obstetrics, University of Pisa, Via Roma 56, Pisa, 56127, Italy. Tel: +3950992609, e-mail: a.gadducci@med.unipi.it

Key Words: Epithelial ovarian cancer, potentially platinum-sensitive recurrence, positron emission tomography/computed tomography, prognosis.
Epithelial ovarian cancer is the gynecological malignancy with the worst prognosis because of the frequent advanced stage at presentation and the elevated biological aggressiveness. Approximately $70-80 \%$ of the patients will develop recurrent disease despite improvement in the primary treatment of the tumor $(1,2)$. Chemotherapy is the standard of care of these patients, whereas secondary cytoreductive surgery should be reserved for accurately selected cases (2-8). Although platinum-free interval (PFI) continues to be an important parameter for the choice of salvage chemotherapy, other factors, (i.e. BRCA status, residual toxicity, eligibility to platinum re-treatment, and patient preference) should be taken into consideration, and on the other hand, the classical categories, platinumrefractory/resistant (PFI $<6$ months), partial-platinum sensitive ( $\mathrm{PFI}=6-12$ months), and platinum-sensitive disease (PFI $>12$ months) have been resized by the Tokyo consensus conference $(8,9)$. The time elapsed since last platinum chemotherapy reflects a continuum of probability of response to further chemotherapy, and moreover the time to recurrence is influenced by type and timing of surveillance procedures. The term platinum-sensitive should be changed into potentially-platinum responsive, corresponding to a patient who responded to prior platinum without early symptomatic relapse. This patient should receive a platinumbased doublet, eventually combined with bevacizumab or followed by PARP inhibitors as maintenance.

2-deoxy-2- $\left[{ }^{18} \mathrm{~F}\right]$-fluorodeoxyglucose (FDG)-positron emission tomography (PET)/computed tomography (CT) is very useful for detecting recurrent ovarian cancer and for identifying the patients who are more likely to benefit from secondary cytoreductive surgery (10-21). 
The maximum standardized uptake value (SUVmax) obtained for a 1-pixel region of interest (ROI) does not necessarily reflect the activity of the whole tumor mass (22). Whole body (wb)-metabolic tumor volume (MTV) and wbtotal lesion glycolysis (TLG) are volume-based parameters developed to measure the metabolic activity in the entire tumor $(23,24)$. Wb-MTV is a volumetric measurement of tumor cells with high glycolytic activity, while wb-TLG is defined as the product of the SUV and the lesion volume.

A systematic review and meta-analysis of literature data have shown that pretreatment volume-based metabolic parameters of ${ }^{18}$ F-FDG-PET can be correlated with the clinical outcome of patients with different malignancies including ovarian cancer (25-32).

In the present retrospective investigation, we assessed the prognostic relevance of SUVmax, wb-MTV and wb-TLG in ${ }^{18}$ F-FDG-PET/CT performed in patients with potentially platinum-responsive recurrent ovarian cancer.

\section{Patients and Methods}

This retrospective investigation assessed 67 patients with potentially platinum-responsive recurrent ovarian cancer who underwent ${ }^{18} \mathrm{~F}$ FDG- PET/CT at the time of first relapse at our Hospital between January 2009 and December 2019. The hospital records, including surgical notes, pathological reports, chemotherapy and follow-up data, were collected using a common form with standardized items.

The tumor stage and histological diagnosis of each case were determined according to the FIGO criteria and the histological typing system of the World Health Organization [WHO], respectively. Tumors were graded as well [G1], moderately [G2], or poorly [G3] differentiated. The baseline characteristics [age, FIGO stage, histological type, tumor grade, presence or absence of ascites, residual disease (RD) after primary debulking or interval debulking surgery, type of first-line chemotherapy] were reported for each case. The total number of first-line chemotherapy cycles ranged from six to eight. The evaluation of the course of disease was based on clinical examination, serum Ca 125 assay, chest x-ray, abdominal-pelvic ultrasound and CT scan. Additional investigations were performed when appropriate.

At the end of primary treatment all the patients were in complete clinical response, defined as the lack of evidence of disease at clinical, serological and imaging examinations, and were then followed-up at regular scheduled intervals with the modalities reported in a previous article (33).

All the patients developed a clinically and/or radiologically detectable first recurrence with a PFI longer than 6 months. A secondary cytoreductive surgery was taken into consideration in patients in good general conditions and performance status $<$ or $=1$ and without ascites, diffuse bulky peritoneal nodules or peritoneal nodules confluent in plaques, mesenteric retraction, and extraabdominal disease (except groin metastases) $(3,9,34)$. Each case had been debated within a multidisciplinary team meeting and discussed with the patient herself. All the patients performed ${ }^{18} \mathrm{~F}$ FDG-PET/CT before any treatment of recurrence.

Image acquisitions. The $\left[{ }^{18} \mathrm{~F}\right] \mathrm{FDG} \mathrm{PET} / \mathrm{CT}$ scans were performed in two different Nuclear Medicine Centers: the Regional Center of Nuclear Medicine at the University Hospital of Pisa and the Nuclear
Medicine Unit at the National Council of Research (CNR) of Pisa. A Discovery 710 scanner (GE Healthcare, Milwaukee, WI, USA) a Discovery VCT scanner (GE Healthcare, Waukesha, WI, USA) with a 3D acquisition modality were used for all the PET/CT studies. All scans were performed with a PET/CT about 60 minutes after the injection of $\left[{ }^{18} \mathrm{~F}\right] \mathrm{FDG}(3.7 \mathrm{MBq} / \mathrm{Kg})$. Low-dose helical CT scan (automatic exposure control with $100 \mathrm{~mA} \max , 120 \mathrm{KVp}$ ) was obtained for attenuation correction with a $3.75-\mathrm{mm}$ slice thickness and 3.27-mm reconstruction interval. During both PET and CT scan patients could breathe freely. Acquisition included the cranial vertex to half thigh, requiring 7 to 9 bed positions. Patients fasted for at least 4 hours and finger stick blood glucose levels were $<200 \mathrm{mg} / \mathrm{dl}$ prior to injection. Images were reconstructed with an iterative algorithm, $256 \times 256$ matrix, and segmented attenuation correction. Oral contrast medium or intravenous contrast medium have not been used.

Analysis criteria. Two readers were aware that patients had been treated for ovarian cancer and had suspected of having a recurrence. However, they were blinded to the patients' prospective PET/CT results. On ${ }^{18} \mathrm{~F}$-FDG-PET/CT images for each patient, in each location, readers recorded the presence/absence of recurrent lesions. Findings were considered positive when SUVmax within the suspected lesion was greater than the liver SUVmax.

Freeware LIFEx software was used to enable calculation of several metabolic indices from the PET images imported in DICOM format on a dedicated personal computer (35). A $40 \%$ threshold of SUVmax was used to segment the volume of each recurrent lesion of ovarian cancer disclosed on the PET/CT images. If physiologic areas of hyperactivity were within the ROI, manual adjustments were performed in order to exclude them from the analysis.

SUVmax, SUVmean, MTV, and TLG, were calculated within the selected ROI. All these parameters were calculated for each site of recurrence, subdivided as follows: pelvis, abdominal peritoneum, retroperitoneal nodes, abdominal parenchymal relapses, extraabdominal relapses. Then, in each patient the global tumor burden was considered for the analysis calculating the wb-MTV and the wb-TLG parameters, that represent the overall volume $(\mathrm{ml})$ and total lesion glycolysis (SUVmean*ml) of the recurrent disease.

Statistical analysis. The time from initial diagnosis to death from any cause or last observation was defined as overall survival. The time from detection of the first recurrence to death from any cause or last observation was defined as post-relapse survival. The analyzed prognostic variables included FIGO stage, histological type, tumor grade, RD after initial surgery, interval time between the last cycle of first-line chemotherapy and first recurrence [time to recurrence], patterns of recurrence treatment at recurrence, SUVmax, wb-MTV and wb-TLG in ${ }^{18}$ F-FDG- PET/CT performed at the time of first recurrence.

Survival analysis were performed according to the Kaplan-Meier product-limit method. Patients were dichotomized based on median cutoff values of age at diagnosis of primary tumor, age at diagnosis of recurrence, time to recurrence, SUVmax, wb-MTV and wb-TLG to determine the association with overall survival and post-relapse survival. A multiple regression analysis based on the Cox proportional hazard model was used to jointly test the relative importance of variables as predictors of survival times. Cox univariable regressions were performed in order to select the factors for the multivariate model. Significance level was set to $5 \%$, and the statistical software R 4.0.3 was used to carried out the analysis. 
Table I. Patient characteristics ( $n=67)$

\begin{tabular}{|c|c|}
\hline Variable & $\mathrm{n}(\%)$ \\
\hline \multicolumn{2}{|l|}{ At presentation } \\
\hline \multicolumn{2}{|l|}{ Age, years } \\
\hline Median (range) & $59(36-77)$ \\
\hline \multicolumn{2}{|l|}{ FIGO stage } \\
\hline I & $4(6)$ \\
\hline II & $2(3)$ \\
\hline III & $60(89.6)$ \\
\hline IV & $1(1.4)$ \\
\hline \multicolumn{2}{|l|}{ Histological type } \\
\hline Serous & $58(86.6)$ \\
\hline Endometrioid & $3(4.5)$ \\
\hline Clear Cell & $3(4.5)$ \\
\hline Mucinous & $1(1.4)$ \\
\hline Mixed & $2(3)$ \\
\hline \multicolumn{2}{|l|}{ Tumor grade } \\
\hline G1-G2 & $8(11.9)$ \\
\hline G3 & $59(88.1)$ \\
\hline \multicolumn{2}{|l|}{ BRCA 1-2 status } \\
\hline Wild type & $32(47.8)$ \\
\hline Unknown & $22(32.8)$ \\
\hline Mutated & $13(19.4)$ \\
\hline \multicolumn{2}{|l|}{ First treatment } \\
\hline PDS + Chemotherapy & $60(89.6)$ \\
\hline NACT + IDS & $7(10.4)$ \\
\hline \multicolumn{2}{|l|}{ RD after surgery } \\
\hline 0 & $46(68.7)$ \\
\hline $0-10 \mathrm{~mm}$ & $13(19.4)$ \\
\hline$>10 \mathrm{~mm}$ & $8(11.9)$ \\
\hline \multicolumn{2}{|l|}{ First-line chemotherapy } \\
\hline PTX/Platinum-based & $38(56.7)$ \\
\hline PTX/Platinum/Bev & $24(35.8)$ \\
\hline Platinum-based & $5(7.5)$ \\
\hline \multicolumn{2}{|l|}{ At recurrence } \\
\hline \multicolumn{2}{|l|}{ Age, years } \\
\hline Median (range) & $61(37-81)$ \\
\hline \multicolumn{2}{|l|}{ Time to recurrence } \\
\hline Median (range) & $22(6-117)$ \\
\hline \multicolumn{2}{|l|}{ Number of recurrence sites } \\
\hline 1 & $48(71.6)$ \\
\hline 2 & $14(20.9)$ \\
\hline$\geq 3$ & $5(7.5)$ \\
\hline \multicolumn{2}{|l|}{ Site of recurrence $(n=94)$} \\
\hline Pelvis & $15(16)$ \\
\hline Abdominal peritoneum & $37(39.4)$ \\
\hline Retroperitoneal nodes & $21(22.3)$ \\
\hline Abdominal parenchymal relapses & $5(5.3)$ \\
\hline Extra-abdominal relapses & $16(17)$ \\
\hline \multicolumn{2}{|l|}{ Treatment } \\
\hline Chemotherapy & $41(61.2)$ \\
\hline SCS + Chemotherapy & $26(38.8)$ \\
\hline \multicolumn{2}{|l|}{ PET/CT parameters (median) } \\
\hline SUVmax & 11.150 \\
\hline Wb-MTV & 7.150 \\
\hline Wb-TLG & 45.920 \\
\hline
\end{tabular}

PDS: Primary debulking surgery; NACT: neo-adjuvant chemotherapy; IDS: interval debulking surgery; RD: residual disease; PTX: paclitaxel; Bev: bevacizumab; SCS: secondary cytoreductive surgery; PET/CT: positron emission tomography/computed tomography; SUVmax: maximum standardized uptake value; wb-MTV: whole body-metabolic tumor volume; wb-TLG: whole body-total lesion glycolysis.

\section{Results}

Patient characteristics at presentation and at the time of recurrence are shown in Table I. Median age of patients at diagnosis was 59 years (Table I). Most of the patients had stage III disease $(89.6 \%)$, had high grade serous histology (86.6\%), had G3 tumor grade (88.1\%), underwent primary debulking surgery (89.6\%), and received platinum/paclitaxelbased chemotherapy with or without bevacizumab (92.5\%). Of the 45 patients tested for germline or somatic $B R C A$ mutations, 13 (28.9\%) had a pathogenic mutation. Median time to first recurrence was 22 months and abdominal peritoneum was the most common site of relapse (39.4\%), followed by retroperitoneal nodes $(22.3 \%)$ and pelvis $(16.0 \%)$. Treatment at recurrence consisted of chemotherapy alone in $61.2 \%$ and secondary cytoreductive surgery plus chemotherapy in $38.8 \%$.

Post-relapse survival and overall survival by prognostic variables are shown in Table II.

At univariate analysis post-relapse survival significantly correlated with RD after primary debulking surgery or interval debulking surgery $(\mathrm{HR}=1.748, p=0.015)$, time to recurrence $(\mathrm{HR}=0.955, p=0.005)$, number of recurrence sites $(\mathrm{HR}=2.260, p=0.001)$, treatment at recurrence $(\mathrm{HR}=0.434$, $p=0.044)$ and MTV $(\mathrm{HR}=1.017, p=0.023)$, but not with SUVmax and wb-TLG (Table III). RD (HR=1.764, $p=0.031$ ), time to recurrence (HR=0.961, $p=0.037$ ), and number of recurrence sites (HR=1.964, $p=0.025)$, but not wb-MTV, were independent prognostic variables for survival after recurrence.

At univariate analysis, overall survival significantly correlated with RD after primary debulking surgery or interval debulking surgery $(\mathrm{HR}=1.596, p=0.049)$, time to recurrence $(\mathrm{HR}=0.939, p=0.0003)$, number of recurrence sites $(\mathrm{HR}=2.474, p=0.0005)$, treatment at recurrence $(\mathrm{HR}=0.431, p=0.043)$ and wb-MTV $(\mathrm{HR}=1.018, p=0.021)$, but not with SUVmax and wb-TLG (Table IV). Time to recurrence $(\mathrm{HR}=0.937, p=0.001)$, and number of recurrence sites $(\mathrm{HR}=1.920, p=0.034)$, but not wb-MTV, were independent prognostic variables for overall survival.

\section{Discussion}

${ }^{18} \mathrm{~F}$-FDG-PET/CT has become a standard imaging method for the staging, monitoring of treatment response, and follow-up of patients with different tumors including ovarian cancer (23).

A meta-analysis of eight studies showed that MTV and TLG were independent prognostic variables for both progressionfree survival $(\mathrm{HR}=2.50,95 \% \mathrm{CI}=1.79-3.48$ and $\mathrm{HR}=2.42$, $95 \% \mathrm{CI}=1.61-3.65$, respectively) and overall survival $(\mathrm{HR}=8.06,95 \% \mathrm{CI}=4.32-15.05$, and $\mathrm{HR}=7.23,95 \% \mathrm{CI}=3.38$ 15.50 , respectively) of patients with ovarian cancer $(29,36-43)$. However, the analyzed studies included patients in different 
Table II. Post-relapse survival and overall survival by Kaplan-Meier analysis.

\begin{tabular}{|c|c|c|c|c|c|}
\hline \multirow[t]{2}{*}{ Variables } & \multirow[b]{2}{*}{ Pts } & \multicolumn{2}{|c|}{ Post-relapse survival } & \multicolumn{2}{|c|}{ Overall survival } \\
\hline & & 2 -years $(\%)$ & 5 -years $(\%)$ & 2 -years $(\%)$ & 5 -years $(\%)$ \\
\hline \multicolumn{6}{|l|}{ Age at diagnosis of primary tumor (years) } \\
\hline$>59$ & 31 & 74.8 & 44.5 & 100 & 61.3 \\
\hline$\leq 59$ & 36 & 85.8 & 55.4 & 100 & 74.3 \\
\hline \multicolumn{6}{|l|}{ FIGO stage } \\
\hline III-IV & 61 & 79.3 & 47.5 & 100 & 67.5 \\
\hline I-II & 6 & 100 & 80 & 100 & 80 \\
\hline \multicolumn{6}{|l|}{ Histological type } \\
\hline Serous & 58 & 81.6 & 46.8 & 100 & 68.9 \\
\hline Other & 9 & 77.8 & 66.7 & 100 & 66.7 \\
\hline \multicolumn{6}{|l|}{ Tumor grade } \\
\hline G3 & 59 & 79.9 & 50.2 & 100 & 65.6 \\
\hline G1-G2 & 8 & 87.5 & 52.5 & 100 & 87.5 \\
\hline \multicolumn{6}{|l|}{ BRCA 1-2 status } \\
\hline Wild type & 32 & 86.4 & 53.8 & 100 & 73.3 \\
\hline Unknown & 22 & 76.1 & 38.7 & 100 & 62.4 \\
\hline Mutated & 13 & 83.9 & 58.7 & 100 & 66.7 \\
\hline \multicolumn{6}{|l|}{ Residual disease $(\mathrm{mm})$} \\
\hline$>10$ & 8 & 42.9 & 21.4 & 100 & 46.9 \\
\hline $0-10$ & 13 & 66.6 & 28.6 & 100 & 59.8 \\
\hline 0 & 46 & 91 & 59.9 & 100 & 74.8 \\
\hline \multicolumn{6}{|l|}{ Age at diagnosis of recurrence (years) } \\
\hline$>61$ & 31 & 78.2 & 48.3 & 100 & 64.7 \\
\hline$\leq 61$ & 36 & 82.9 & 52.4 & 100 & 71.5 \\
\hline \multicolumn{6}{|l|}{ Time to recurrence (months) } \\
\hline$\leq 22$ & 35 & 66.9 & 33.6 & 100 & 37.9 \\
\hline$>22$ & 32 & 96.8 & 69.3 & 100 & 100 \\
\hline \multicolumn{6}{|l|}{ Recurrence site } \\
\hline Pelvis and/or abdominal peritoneum and/or retroperitoneal nodes & 48 & 80.1 & 58.7 & 100 & 76.1 \\
\hline Abdominal parenchymal relapses and/or extra-abdominal relapses & 19 & 83 & 28 & 100 & 49.9 \\
\hline \multicolumn{6}{|l|}{ Number of recurrence sites } \\
\hline$\geq 3$ & 5 & 75 & 0 & 100 & 25 \\
\hline 2 & 14 & 57.1 & 10.7 & 100 & 42.9 \\
\hline 1 & 48 & 88.9 & 66.3 & 100 & 80.3 \\
\hline \multicolumn{6}{|l|}{ Treatment of recurrence } \\
\hline Chemotherapy & 41 & 77.1 & 41.3 & 100 & 59.1 \\
\hline SCS + Chemotherapy & 26 & 87.8 & 64 & 100 & 83.8 \\
\hline \multicolumn{6}{|l|}{ SUVmax } \\
\hline$>11.150$ & 33 & 72.5 & 49 & 100 & 59.8 \\
\hline$\leq 11.150$ & 34 & 90 & 50.8 & 100 & 78 \\
\hline \multicolumn{6}{|l|}{ Wb-MTV } \\
\hline$>7.150$ & 33 & 81 & 40.9 & 100 & 61.9 \\
\hline$\leq 7.150$ & 34 & 80.9 & 60.8 & 100 & 75.1 \\
\hline \multicolumn{6}{|l|}{ Wb-TLG } \\
\hline$>45.920$ & 33 & 71.8 & 31.8 & 100 & 56 \\
\hline$\leq 45.920$ & 34 & 90.5 & 73.0 & 100 & 81.1 \\
\hline
\end{tabular}

Pts: Patients; SCS: secondary cytoreductive surgery; SUVmax: maximum standardized uptake value; wb-MTV: whole body-metabolic tumor volume; wb-TLG: whole body-total lesion glycolysis.

phases of disease, i.e. before primary surgery, after primary surgery, after neo-adjuvant chemotherapy and at the time of recurrence. Chung et al. (36) retrospectively assessed 55 patients who underwent ${ }^{18} \mathrm{~F}$-FDG-PET/CT before initial surgery. High MTV and high TLG values were independent prognostic factors for shorter progression-free survival $(\mathrm{HR}=5.571, \quad 95 \% \mathrm{CI}=1.279-24.272$, and $\mathrm{HR}=2.967$, $95 \% \mathrm{CI}=1.065-8.265$, respectively). In a retrospective investigation of 175 patients, TLG of ${ }^{18} \mathrm{~F}-\mathrm{FDG}-\mathrm{PET} / \mathrm{CT}$ performed prior to cytoreductive surgery independently 
Table III. Post-relapse survival by Cox proportional-hazard model.

\begin{tabular}{|c|c|c|c|c|c|c|}
\hline \multirow[t]{2}{*}{ Variables } & \multicolumn{3}{|c|}{ Univariate analysis } & \multicolumn{3}{|c|}{ Multivariate analysis } \\
\hline & HR & $95 \% \mathrm{CI}$ & $p$-Value & HR & $95 \% \mathrm{CI}$ & $p$-Value \\
\hline Age at diagnosis of primary tumor & 1.028 & $0.990-1.068$ & 0.149 & & & \\
\hline FIGO stage & 3.723 & $0.506-27.380$ & 0.197 & & & \\
\hline Histological type & 1.310 & $0.455-3.770$ & 0.616 & & & \\
\hline Tumor grade & 1.490 & $0.451-4.924$ & 0.513 & & & \\
\hline BRCA 1-2 status* & 1.103 & $0.378-3.216$ & 0.858 & & & \\
\hline Residual disease & 1.748 & $1.113-2.745$ & 0.015 & 1.764 & $1.055-2.951$ & 0.031 \\
\hline Age at diagnosis of recurrence & 1.019 & $0.981-1.058$ & 0.334 & & & \\
\hline Time to recurrence & 0.955 & $0-0.986$ & 0.005 & 0.961 & $0-0.998$ & 0.037 \\
\hline Recurrence site & 2.039 & $0.949-4.383$ & 0.068 & & & \\
\hline Number of recurrence sites & 2.260 & $1.404-3.639$ & 0.001 & 1.964 & $1.090-3.536$ & 0.025 \\
\hline Treatment of recurrence & 0.434 & $0-0.978$ & 0.044 & 0.972 & $0.398-2.374$ & 0.950 \\
\hline SUVmax & 1.011 & $0.988-1.034$ & 0.368 & & & \\
\hline Wb-MTV & 1.017 & $1.002-1.033$ & 0.023 & 0.997 & $0.978-1.016$ & 0.727 \\
\hline Wb-TLG & 1.001 & $0.999-1.003$ & 0.267 & & & \\
\hline
\end{tabular}

HR: Hazard ratio; CI: confidence interval; FIGO: Federation Internationale de Gynecologie et d'Obstetrique; SUVmax: maximum standardized uptake value; wb-MTV, whole body-metabolic tumor volume; wb-TLG: whole body-total lesion glycolysis. *Wild type versus mutated.

Table IV. Overall survival by Cox proportional-hazard model.

\begin{tabular}{|c|c|c|c|c|c|c|}
\hline \multirow[t]{2}{*}{ Variables } & \multicolumn{3}{|c|}{ Univariate analysis } & \multicolumn{3}{|c|}{ Multivariate analysis } \\
\hline & HR & $95 \% \mathrm{CI}$ & $p$-Value & HR & $95 \% \mathrm{CI}$ & $p$-Value \\
\hline Age at diagnosis of primary tumor & 1.021 & $0.984-1.059$ & 0.266 & & & \\
\hline FIGO stage & 3.568 & $0.484-26.280$ & 0.212 & & & \\
\hline Histological type & 1.271 & $0.442-3.653$ & 0.657 & & & \\
\hline Tumor grade & 1.534 & $0.464-5.067$ & 0.483 & & & \\
\hline BRCA $1-2$ status* & 0.985 & $0.341-2.845$ & 0.978 & & & \\
\hline Residual disease & 1.596 & $1.001-2.545$ & 0.049 & 1.657 & $0.977-2.811$ & 0.061 \\
\hline Age at diagnosis of recurrence & 1.009 & $0.973-1.046$ & 0.631 & & & \\
\hline Time to recurrence & 0.939 & $0-0.971$ & 0.0003 & 0.937 & $0-0.975$ & 0.001 \\
\hline Recurrence site & 1.819 & $0.858-3.855$ & 0.119 & & & \\
\hline Number of recurrence sites & 2.474 & $1.491-4.105$ & 0.0005 & 1.920 & $1.052-3.503$ & 0.034 \\
\hline Treatment of recurrence & 0.431 & $0-0.974$ & 0.043 & 0.918 & $0.382-2.203$ & 0.848 \\
\hline SUVmax & 1.014 & $0.991-1.038$ & 0.230 & & & \\
\hline Wb-MTV & 1.018 & $1.003-1.033$ & 0.021 & 0.999 & $0.981-1.018$ & 0.932 \\
\hline Wb-TLG & 1.001 & $0.999-1.003$ & 0.179 & & & \\
\hline
\end{tabular}

HR: Hazard ratio; CI: confidence interval; FIGO, Federation Internationale de Gynecologie et d'Obstetrique; SUVmax: maximum standardized uptake value; wb-MTV: whole body-metabolic tumor volume; wb-TLG: whole body-total lesion glycolysis. *Wild type versus mutated.

correlated with progression-free survival $(p=0.008)$, whereas SUVmax and MTV were associated with progression-free survival at univariate but not at multivariate analysis $(p<0.05)$ (38). TLG was an independent predictor of overall survival $(\mathrm{HR}=1.043,95 \% \mathrm{CI}=1.01-1.078)$ in series of 47 patients who underwent ${ }^{18}$ F-FDG-PET/CT after surgery (37). SUVmax was not related to overall survival in a series of 31 patients who underwent ${ }^{18}$ F-FDG-PET/CT for an early restaging after cytoreductive surgery (42). There was a significant longer overall survival in patients with high MTV than those with lower MTV $(p=0.01)$, whereas TLG had no significant prognostic relevance. MTV reduction after neoadjuvant chemotherapy independently correlated with progression-free survival in a series of 29 patients with advanced disease (43).

Only three studies have assessed the prognostic relevance of volume-based parameters of ${ }^{18} \mathrm{~F}-\mathrm{FDG}-$ 
PET/CT in patients with recurrent ovarian cancer (39-41). MTV and TLG independently correlated with post-relapse survival $(\mathrm{HR}=1.36,95 \% \mathrm{CI}=1.2-1.6$ and $\mathrm{HR}=2.24$, $95 \% \mathrm{CI}=1.4-3.5$, respectively) in a series of 56 patients at first recurrence with a median PFI of 10 months (range=0106 months) (39). Mayoral et al. (41) reported that MTV and TLG, but not SUVmax, were significant predictors of progression-free survival at univariate analysis in a study including 26 patients with a median PFI of 19.5 months (range=2-144 months). MTV and TLG, but not SUVmax, were associated with debulking status in 55 patients who underwent ${ }^{18} \mathrm{~F}$-FDG-PET/CT before secondary cytoreductive surgery (40). Patients with high MTV and/or high TLG had significantly shorter progression-free survival at univariate analysis.

In the present investigation, that included 67 patients with potentially platinum-responsive recurrent ovarian cancer, RD after initial surgery, time to recurrence and number of recurrence sites were independent prognostic variables for post-relapse survival and time to recurrence and number of recurrence sites were independent prognostic factors for overall survival. Wb-MTV, but not SUVmax and wb-TLG, of the ${ }^{18}$ F-FDG-PET/CT performed before any treatment of recurrence (chemotherapy or secondary cytoreductive surgery) correlated with both post-relapse survival $(\mathrm{HR}=1.017,95 \% \mathrm{CI}=1.002-1.033, p=0.023)$ and overall survival $(\mathrm{HR}=1.018,95 \% \mathrm{CI}=1.003-1.033, p=0.021)$ at univariate analysis, but failed to retain statistical significance at multivariate analysis. The lack of any prognostic relevance of SUV can be at least partially explained by the fact that it is a single-voxel measurement that does not consider the number of voxels included in the tumor volume (40). Therefore, it may be easily affected by statistical noise and not reflect the metabolism of the whole tumor burden. The reason why only the wb-MTV has presented a statistical significance could be explained by the fact that, while the MTV essentially represents the disease burden expressed in $\mathrm{ml}$, the TLG is partly affected by the heterogeneity of the SUV values of the different lesions disclosed in each patient. Thus, what seems to be more relevant from a prognostic point of view is the overall amount of the recurrent disease rather than the total metabolic activity of the disease itself.

In conclusion, in our experience a volume-based parameter of ${ }^{18}$ F-FDG-PET/CT such as the wb-MTV of recurrent disease may have a better prognostic significance than SUVmax, however, it seems to be not an independent predictor of clinical outcome in patients with potentially platinum-responsive recurrent ovarian cancer.

\section{Conflicts of Interest}

The Authors declare no conflicts of interest regarding this study.

\section{Authors' Contributions}

Study concepts: A.G; D.V.; Study design: A.G., E.S., S.C., D.V. Recruitment and quality control of data: A.G., E.S., G.M, F.G., A. G., T. D., S.C. Data analysis and interpretation: A.G., E.S., G.M, F.G, D.V. Statistical analysis: M.M. Article preparation: A.G.; Article editing: All Authors; Article review: All Authors.

\section{References}

1 Gadducci A and Cosio S: Surveillance of patients after initial treatment of ovarian cancer. Crit Rev Oncol Hematol 71(1): 43-52, 2009. PMID: 19179092. DOI: 10.1016/j.critrevonc.2008.12.008

2 Pignata S, C Cecere S, Du Bois A, Harter P and Heitz F: Treatment of recurrent ovarian cancer. Ann Oncol 28(suppl_8): viii51-viii56, 2017. PMID: 29232464. DOI: 10.1093/annonc/mdx441

3 Harter P, du Bois A, Hahmann M, Hasenburg A, Burges A, Loibl S, Gropp M, Huober J, Fink D, Schröder W, Muenstedt K, Schmalfeldt B, Emons G, Pfisterer J, Wollschlaeger K, Meerpohl HG, Breitbach GP, Tanner B, Sehouli J, Arbeitsgemeinschaft Gynaekologische Onkologie Ovarian Committee and AGO Ovarian Cancer Study Group: Surgery in recurrent ovarian cancer: the Arbeitsgemeinschaft Gynaekologische Onkologie (AGO) DESKTOP OVAR trial. Ann Surg Oncol 13(12): 1702-1710, 2006. PMID: 17009163. DOI: 10.1245/s10434-006-9058-0

4 Bommert M, Harter P, Heitz F and du Bois A: When should Surgery be used for Recurrent Ovarian Carcinoma? Clin Oncol (R Coll Radiol) 30(8): 493-497, 2018. PMID: 29743148. DOI: 10.1016/j.clon.2018.04.006

5 Colombo N, Sessa C, du Bois A, Ledermann J, McCluggage WG, McNeish I, Morice P, Pignata S, Ray-Coquard I, Vergote I, Baert T, Belaroussi I, Dashora A, Olbrecht S, Planchamp F, Querleu D and ESMO-ESGO ovarian cancer consensus conference working group: ESMO-ESGO consensus conference recommendations on ovarian cancer: Pathology and molecular biology, early and advanced stages, borderline tumours and recurrent disease. Ann Oncol 30(5): 672-705, 2019. PMID: 31046081. DOI: 10.1093/annonc/mdz062

6 Armstrong DK, Alvarez RD, Bakkum-Gamez JN, Barroilhet L, Behbakht K, Berchuck A, Berek JS, Chen LM, Cristea M, DeRosa M, ElNaggar AC, Gershenson DM, Gray HJ, Hakam A, Jain A, Johnston C, Leath CA III, Liu J, Mahdi H, Matei D, McHale M, McLean K, O’Malley DM, Penson RT, Percac-Lima S, Ratner E, Remmenga SW, Sabbatini P, Werner TL, Zsiros E, Burns JL and Engh AM: NCCN guidelines insights: Ovarian cancer, Version 1.2019. J Natl Compr Canc Netw 17(8): 896909, 2019. PMID: 31390583. DOI: 10.6004/jnccn.2019.0039

7 Du Bois A, Sehouli J, Vergote I, Ferron G, Reuss A, Meier W, Greggi S, Jensen PT, Selle F, Guyon F, Pomel C, Lecuru F, Zang R, Avall-Lundqvis E, Kim JW, Ponce J, Raspagliesi F, GhaemMaghami S, Reinthaller A and Harter P: Randomized phase III study to evaluate the impact of secondary cytoreductive surgery in recurrent ovarian cancer: AGO final analysis of AGO DESKTOP III/ENGOT ov20. J Clin Oncol 38(Suppl): Abstr 6000, 2020.

8 Gadducci A, Aletti GD, Landoni F, Lazzari R, Mangili G, Olivas P, Pignata S, Salutari V, Sartori E, Scambia G, Zannoni GF, Sabbatini R and Lorusso D: Management of ovarian cancer: Guidelines of the Italian Medical Oncology Association (AIOM). Tumori: 300891620966382, 2020. PMID: 33106117. DOI: $10.1177 / 0300891620966382$ 
9 Wilson MK, Pujade-Lauraine E, Aoki D, Mirza MR, Lorusso D Oza AM, du Bois A, Vergote I, Reuss A, Bacon M, Friedlander M, Gallardo-Rincon D, Joly F, Chang SJ, Ferrero AM, Edmondson RJ, Wimberger P, Maenpaa J, Gaffney D, Zang R, Okamoto A, Stuart G, Ochiai K and participants of the fifth ovarian cancer consensus conference: Fifth ovarian cancer consensus conference of the gynecologic cancer intergroup: Recurrent disease. Ann Oncol 28(4): 727-732, 2017. PMID: 27993805. DOI: $10.1093 /$ annonc/mdw663

10 Bristow RE, del Carmen MG, Pannu HK, Cohade C, Zahurak ML, Fishman EK, Wahl RL and Montz FJ: Clinically occult recurrent ovarian cancer: Patient selection for secondary cytoreductive surgery using combined PET/CT. Gynecol Oncol 90(3): 519-528, 2003. PMID: 13678719. DOI: 10.1016/s0090-8258(03)00336-6

11 Chung HH, Kang WJ, Kim JW, Park NH, Song YS, Chung JK, Kang SB and Lee HP: Role of $\left[{ }^{18} \mathrm{~F}\right] \mathrm{FDG}$ PET/CT in the assessment of suspected recurrent ovarian cancer: Correlation with clinical or histological findings. Eur J Nucl Med Mol Imaging 34(4): 480-486, 2007. PMID: 17089122. DOI: 10.1007/ s00259-006-0260-x

12 Risum S, Høgdall C, Markova E, Berthelsen AK, Loft A, Jensen F, Høgdall E, Roed H and Engelholm SA: Influence of 2-( $\left.{ }^{18} \mathrm{~F}\right)$ fluoro-2-deoxy-D-glucose positron emission tomography/computed tomography on recurrent ovarian cancer diagnosis and on selection of patients for secondary cytoreductive surgery. Int J Gynecol Cancer 19(4): 600-604, 2009. PMID: 19509556. DOI: 10.1111/ IGC.0b013e3181a3cc94

13 Sala E, Kataoka M, Pandit-Taskar N, Ishill N, Mironov S, Moskowitz CS, Mironov O, Collins MA, Chi DS, Larson S and Hricak H: Recurrent ovarian cancer: Use of contrast-enhanced $\mathrm{CT}$ and PET/CT to accurately localize tumor recurrence and to predict patients' survival. Radiology 257(1): 125-134, 2010. PMID: 20697116. DOI: 10.1148/radiol.10092279

14 Pan HS, Lee SL, Huang LW and Chen YK: Combined positron emission tomography-computed tomography and tumor markers for detecting recurrent ovarian cancer. Arch Gynecol Obstet 283(2): 335-341, 2011. PMID: 20221620. DOI: 10.1007/s00404010-1404-6

15 Sari O, Kaya B, Kara PO, Gedik GK, Celik C, Ozbek O and Serdengecti M: The role of FDG-PET/CT in ovarian cancer patients with high tumor markers or suspicious lesion on contrast-enhanced CT in evaluation of recurrence and/or in determination of intraabdominal metastases. Rev Esp Med Nucl Imagen Mol 31(1): 3-8, 2012. PMID: 21549452. DOI: 10.1016/j.remn.2011.03.008

16 Tawakol A, Abdelhafez YG, Osama A, Hamada E and El Refaei $\mathrm{S}$ : Diagnostic performance of ${ }^{18} \mathrm{~F}-\mathrm{FDG}$ PET/contrast-enhanced CT versus contrast-enhanced $\mathrm{CT}$ alone for post-treatment detection of ovarian malignancy. Nucl Med Commun 37(5): 453-460, 2016. PMID: 26745811. DOI: 10.1097/MNM.0000000000000477

17 Lee YJ, Kim YM, Jung PS, Lee JJ, Kim JK, Kim YT and Nam JH: Diagnostic value of integrated ${ }^{18} \mathrm{~F}$-fluoro-2-deoxyglucose positron emission tomography/computed tomography in recurrent epithelial ovarian cancer: Accuracy of patient selection for secondary cytoreduction in 134 patients. J Gynecol Oncol 29(3): e36, 2018. PMID: 29400023. DOI: 10.3802/jgo.2018.29.e36

18 Gadducci A, Simonetti E, Manca G, Guidoccio F, Fanucchi A, Cosio S and Volterrani D: Positron emission tomography/computed tomography in platinum-sensitive recurrent ovarian cancer: A single-center Italian study. Anticancer Res 40(4): 2191-2197, 2020. PMID: 32234914. DOI: 10.21873/anticanres.14180
19 Vargas HA, Burger IA, Goldman DA, Miccò M, Sosa RE, Weber W, Chi DS, Hricak H and Sala E: Volume-based quantitative FDG PET/CT metrics and their association with optimal debulking and progression-free survival in patients with recurrent ovarian cancer undergoing secondary cytoreductive surgery. Eur Radiol 25(11): 3348-3353, 2015. PMID: 25916387. DOI: $10.1007 / \mathrm{s} 00330-015-3729-9$

20 Fanfani F, Monterossi G, Fagotti A, Gallotta V, Costantini B, Vizzielli G, Petrillo M, Carbone MV and Scambia G: Positron emission tomography-laparoscopy based method in the prediction of complete cytoreduction in platinum-sensitive recurrent ovarian cancer. Ann Surg Oncol 22(2): 649-654, 2015. PMID: 25155399. DOI: 10.1245/s10434-014-4011-0

21 Amit A, Hodes A, Lavie O, Keidar Z, Matanes E and Lowenstein L: The role of F18-FDG PET/CT in predicting secondary optimal de-bulking in patients with recurrent ovarian cancer. Surg Oncol 26(4): 347-351, 2017. PMID: 29113651. DOI: $10.1016 /$ j.suronc.2017.07.004

22 Soret M, Bacharach SL and Buvat I: Partial-volume effect in PET tumor imaging. J Nucl Med 48(6): 932-945, 2007. PMID: 17504879. DOI: 10.2967/jnumed.106.035774

23 Larson SM, Erdi Y, Akhurst T, Mazumdar M, Macapinlac HA, Finn RD, Casilla C, Fazzari M, Srivastava N, Yeung HW, Humm JL, Guillem J, Downey R, Karpeh M, Cohen AE and Ginsberg R: Tumor treatment response based on visual and quantitative changes in global tumor glycolysis using PET-FDG imaging. The visual response score and the change in total lesion glycolysis. Clin Positron Imaging 2(3): 159-171, 1999. PMID: 14516540. DOI: 10.1016/s1095-0397(99)00016-3

24 Moon SH, Hyun SH and Choi JY: Prognostic significance of volume-based PET parameters in cancer patients. Korean J Radiol 14(1): 1-12, 2013. PMID: 23323025. DOI: 10.3348/kjr.2013.14.1.1

25 Im HJ, Pak K, Cheon GJ, Kang KW, Kim SJ, Kim IJ, Chung JK, Kim EE and Lee DS: Prognostic value of volumetric parameters of (18)F-FDG PET in non-small-cell lung cancer: A metaanalysis. Eur J Nucl Med Mol Imaging 42(2): 241-251, 2015. PMID: 25193652. DOI: 10.1007/s00259-014-2903-7

26 Pak K, Cheon GJ, Nam HY, Kim SJ, Kang KW, Chung JK, Kim EE and Lee DS: Prognostic value of metabolic tumor volume and total lesion glycolysis in head and neck cancer: A systematic review and meta-analysis. J Nucl Med 55(6): 884-890, 2014. PMID: 24752671. DOI: 10.2967/jnumed.113.133801

27 Zhu D, Wang L, Zhang H, Chen J, Wang Y, Byanju S and Liao M: Prognostic value of $18 \mathrm{~F}-\mathrm{FDG}-\mathrm{PET} / \mathrm{CT}$ parameters in patients with pancreatic carcinoma: A systematic review and metaanalysis. Medicine (Baltimore) 96(33): e7813, 2017. PMID: 28816978. DOI: 10.1097/MD.0000000000007813

28 Han S, Kim H, Kim YJ, Suh CH and Woo S: Prognostic value of volume-based metabolic parameters of ${ }^{18} \mathrm{~F}-\mathrm{FDG}$ PET/CT in uterine cervical cancer: A systematic review and meta-analysis. AJR Am J Roentgenol 211(5): 1112-1121, 2018. PMID: 30207790. DOI: $10.2214 /$ AJR.18.19734

29 Han S, Kim H, Kim YJ, Suh CH and Woo S: Prognostic value of volume-based metabolic parameters of $18 \mathrm{~F}-\mathrm{FDG}$ PET/CT in ovarian cancer: A systematic review and meta-analysis. Ann Nucl Med 32(10): 669-677, 2018. PMID: 30101392. DOI: 10.1007/s12149-018-1289-1

30 Rijo-Cedeño J, Mucientes J, Álvarez O, Royuela A, Seijas Marcos S, Romero J and García-Berrocal JR: Metabolic tumor volume and total lesion glycolysis as prognostic factors in head 
and neck cancer: Systematic review and meta-analysis. Head Neck 42(12): 3744-3754, 2020. PMID: 32914474. DOI: 10.1002/hed.26461

31 Xuan D, Wen W, Tian S, Piao M, Xu D and Liu L: Prognostic value of maximum standard uptake value, metabolic tumor volume, and total lesion glycolysis of ${ }^{18} \mathrm{~F}-\mathrm{FDG} \mathrm{PET} / \mathrm{CT}$ in patients with renal carcinoma: A protocol for systematic review and meta analysis. Medicine (Baltimore) 99(20): e19988, 2020. PMID: 32443301. DOI: 10.1097/MD.0000000000019988

32 Pak K, Seok JW, Kim HY, Nguyen TL, Kim K, Kim SJ, Kim IJ and Hopper J: Prognostic value of metabolic tumor volume and total lesion glycolysis in breast cancer: A meta-analysis. Nucl Med Commun 41(8): 824-829, 2020. PMID: 32516244. DOI: 10.1097/MNM.0000000000001227

33 Gadducci A, Fuso L, Cosio S, Landoni F, Maggino T, Perotto S, Sartori E, Testa A, Galletto L and Zola P: Are surveillance procedures of clinical benefit for patients treated for ovarian cancer? A retrospective Italian multicentric study. Int J Gynecol Cancer 19(3): 367-374, 2009. PMID: 19407561. DOI: 10.1111/IGC.0b013e3181a1cc02

34 Coleman RL, Spirtos NM, Enserro D, Herzog TJ, Sabbatini P, Armstrong DK, Kim JW, Park SY, Kim BG, Nam JH, Fujiwara K, Walker JL, Casey AC, Alvarez Secord A, Rubin S, Chan JK, DiSilvestro P, Davidson SA, Cohn DE, Tewari KS, BasenEngquist K, Huang HQ, Brady MF and Mannel RS: Secondary surgical cytoreduction for recurrent ovarian cancer. N Engl J Med 381(20): 1929-1939, 2019. PMID: 31722153. DOI: 10.1056/NEJMoa1902626

35 Nioche C, Orlhac F, Boughdad S, Reuzé S, Goya-Outi J, Robert C, Pellot-Barakat C, Soussan M, Frouin F and Buvat I: LIFEx: A Freeware for radiomic feature calculation in multimodality imaging to accelerate advances in the characterization of tumor heterogeneity. Cancer Res 78(16): 4786-4789, 2018. PMID: 29959149. DOI: $10.1158 / 0008-5472$

36 Chung HH, Kwon HW, Kang KW, Park NH, Song YS, Chung JK, Kang SB and Kim JW: Prognostic value of preoperative metabolic tumor volume and total lesion glycolysis in patients with epithelial ovarian cancer. Ann Surg Oncol 19(6): 1966-1972, 2012. PMID: 22124757. DOI: 10.1245/s10434-011-2153-x

37 Liao S, Lan X, Cao G, Yuan H and Zhang Y: Prognostic predictive value of total lesion glycolysis from ${ }^{18} \mathrm{~F}-\mathrm{FDG}$ PET/CT in post-surgical patients with epithelial ovarian cancer. Clin Nucl Med 38(9): 715-720, 2013. PMID: 23856825. DOI: 10.1097/RLU.0b013e31829f57fa
38 Lee JW, Cho A, Lee JH, Yun M, Lee JD, Kim YT and Kang WJ: The role of metabolic tumor volume and total lesion glycolysis on ${ }^{18} \mathrm{~F}-\mathrm{FDG} \mathrm{PET} / \mathrm{CT}$ in the prognosis of epithelial ovarian cancer. Eur J Nucl Med Mol Imaging 41(10): 1898-1906, 2014. PMID: 24852188. DOI: 10.1007/s00259-014-2803-x

39 Kim CY, Jeong SY, Chong GO, Son SH, Jung JH, Kim DH, Lee SW, Ahn BC and Lee J: Quantitative metabolic parameters measured on F-18 FDG PET/CT predict survival after relapse in patients with relapsed epithelial ovarian cancer. Gynecol Oncol 136(3): 498-504, 2015. PMID: 25557270. DOI: 10.1016/j.ygyno. 2014.12.032

40 Vargas HA, Burger IA, Goldman DA, Miccò M, Sosa RE, Weber W, Chi DS, Hricak H and Sala E: Volume-based quantitative FDG PET/CT metrics and their association with optimal debulking and progression-free survival in patients with recurrent ovarian cancer undergoing secondary cytoreductive surgery. Eur Radiol 25(11): 3348-3353, 2015. PMID: 25916387. DOI: $10.1007 / \mathrm{s} 00330-015-3729-9$

41 Mayoral M, Fernandez-Martinez A, Vidal L, Fuster D, Aya F, Pavia J, Pons F, Lomeña F and Paredes P: Prognostic value of (18)F-FDG PET/CT volumetric parameters in recurrent epithelial ovarian cancer. Rev Esp Med Nucl Imagen Mol 35(2): 88-95, 2016. PMID: 26541072. DOI: 10.1016/j.remn.2015.08.005

42 Gallicchio R, Nardelli A, Venetucci A, Capacchione D, Pelagalli A, Sirignano C, Mainenti P, Pedicini P, Guglielmi G and Storto G: F-18 FDG PET/CT metabolic tumor volume predicts overall survival in patients with disseminated epithelial ovarian cancer. Eur J Radiol 93: 107-113, 2017. PMID: 28668403. DOI: 10.1016/j.ejrad.2017.05.036

43 Vallius T, Hynninen J, Kemppainen J, Alves V, Auranen K, Matomäki J, Oksa S, Virtanen J, Grénman S, Auranen A and Seppänen M: ${ }^{18}$ F-FDG-PET/CT based total metabolic tumor volume change during neoadjuvant chemotherapy predicts outcome in advanced epithelial ovarian cancer. Eur J Nucl Med Mol Imaging 45(7): 1224-1232, 2018. PMID: 29476227. DOI: 10.1007/s00259-018-3961-z 